\title{
COOPERATIVE LEARNING: STRATEGI PENGEMBANGAN INOVASI PENDIDIKAN DI INDONESIA
}

\author{
Meidawati Suswandari \\ PGSD FKIP Universitas Veteran Bangun Nusantara, Sukoharjo \\ Email; moetis meida@yahoo.co.id
}

\begin{abstract}
This study aims to critically analyze Education innovation in Indonesia through twentyfour precise strategies of Education strategy. This type of research is library research. Data collection by identifying discourses from books, papers or articles, journals, newspapers, internet (web), or other information related to education. Data analysis uses descriptive analysis, content analysis, and scientifically critical analysis. The results of the study show that Educational innovation in Indonesia can apply twenty-four Educational strategies which include Personalization, Multi-Age Classes, Small Community Learning, Peer Group Learning, Small Group Learning Communities with other groups, Multidisciplinary Curriculum with Block Scheduling, Cooperative Learning, Cooperative Learning, Based Learning Projects, Instruction Associates, Teaching Teams, Community Service Learning, Looping Partnerships, Businesses for Assessments, Resources and Funding, Global Connections, Laptops and Wireless Technology for Learning Wherever and Anytime, Parent Engagement, Students Showing Shows, Life Skills Curriculum (Non- Academic), Meaningful Career Counseling, Social / Emotional Counseling, Open Learning, Education to serve Student Needs, Portfolio-Based Assessment and the New Paradigm of School Buildings.

Keywords: twenty four, educational innovation
\end{abstract}

\section{Pendahuluan}

Perkembangan yang terjadi pada seluruh bidang di Indonesia, termasuk pada bidang pendidikan diharapkan berbanding lurus dengan kualitas sumber daya manusia yang seharusnya semakin tinggi Maka, secara tidak langsung memberikan acuan pada pelaku kebijakan untuk mengembangkan dunia pendidikan. Ungkapan dari Budiardjo (Subandi, 2005: 13) menyatakan bahwa kebijakan adalah sekumpulan keputusan yang diambil oleh seorang pelaku atau kelompok politik dalam usaha memilih tujuan-tujuan tersebut. Pada prinsipnya, pihak yang membuat kebijakan-kebijakan itu mempunyai kekuasaan untuk melaksanakannya.

Berbagai kebijakan dalam bidang pendidikan diharapkan mampu menjadi jalan keluar yang baik bagi kemajuan pendidikan Indonesia. Salah satunya kebijakan dari PT Eduspek Indonesia meluncurkan e-Sabak, sebuah inovasi pendidikan yang menerapkan pembelajaran abad-21 di sekolah. E-Sabak merupakan Sistem Aplikasi Belajar Aktif dan Kreatif elektronik (Sabak) menggunakan sabak atau tablet elektronik. Saat ini, sudah ada sekitar 88 sekolah di seluruh Indonesia yang menyatakan minatnya untuk mengaplikasikan sistem ini. Dampak positif dari sistem ini memungkinkan siswa untuk belajar secara online, mengubah sikap belajar dan memberi peluang bagi guru untuk meningkatkan produktifitas sekaligus menciptakan suasana belajar yang baru untuk membantu sistem pembelajaran siswa. Perangkat lunak, disediakan 
antara lain oleh Intel Education Lab, Intel Education Media Camera, SPARKvue, ArtRage, Fun With Construction, Kno, Foxit Reader, Insight dan Deep Freeze. Program e-Sabak yang ditawarkan secara lengkap dengan kisaran harga Rp 1,2 Miliar.

Fenomena di atas, merujuk pada konsep peningkatan kualitas pendidikan di Indonesia dengan menginovasi kurikulum yang tercantum dalam Kepmendiknas No.232/U/2000 dan No.45/U/2002 yang bertujuan untuk seperti: (a) persaingan di dunia global, yang berakibat juga terhadap persaingan perguruan tinggi di dalam negeri maupun di luar negeri, sehingga perguruan tinggi dituntut untuk menghasilkan lulusan yang dapat bersaing dalam dunia global; (b) adanya perubahan orientasi pendidikan tinggi yang tidak lagi hanya menghasilkan manusia cerdas berilmu tetapi juga yang mampu menerapkan keilmuannya dalam kehidupan di masyarakatnya (kompeten dan relevan), yang lebih berbudaya; dan (c) Juga adanya perubahan kebutuhan di dunia kerja yang terwujud dalam perubahan persyaratan dalam menerima tenaga kerja, yaitu adanya persyaratan softskills yang dominan disamping hardskills-nya. Kurikulum yang dikonsepkan lebih didasarkan pada rumusan kompetensi yang harus dicapai/dimiliki oleh lulusan perguruan tinggi yang sesuai atau mendekati kompetensi yang dibutuhkan oleh masyarakat pemangku kepentingan/stakeholders.

Oleh sebab itu, generasi penerus memiliki kewajiban untuk membangun dunia pendidikan semakin berkualitas dan berkuantitas apalagi munculnya persaingan secara regional, nasional, dan internasional semakin menuntut kita menjadi bangsa yang unggul, kompeten, dan berkarakter. Kerangka pembangunan pendidikan salah satunya dengan adanya inovasi dalam dunia pendidikan. Inovasi di dunia pendidikan akan terwujud melalui adanya strategi pendidikan yang direncanakan secara matang.

Di sisi lain, kita perlu tahu apa yang menjadi istilah tentang inovasi. Everett M. Rogers (2003: 12) mengemukakan bahwa inovasi merupakan rangkaian ide, praktik, atau proyek baru yang saling terkait dengan unit individu satu dengan lainnya yang di dalamnya terdapat proses adopsi. Hal lain dikemukakan Pervaiz dan Charles D (Endang W, 2008: 2) bahwa inovasi tidak terbatas pada benda atau barang hasil produksi, tetapi juga meliputi sikap hidup, perilaku, atau gerakan-gerakan menuju proses perubahan di dalam segala bentuk tata kehidupan masyarakat. Oleh sebab itu, inovasi menjadi rangkaian perubahan yang direncanakan dan bertujuan untuk memperbaiki praktik-praktik. Sementara itu, pendapat lain menyebutkan bahwa inovasi adalah suatu pengenalan hal-hal yang baru, masukan, pembaharuan, penemuan baru dari hal-hal yang 
sudah ada atau dikenal sebelumnya baik berupa gagasan metode maupun alat (Depdikbud, 1990: 333).

Pengenalan hak yang baru yang dahulunya telah ada dan belum ada tersebut, menjadi faktor penentu inovasi untuk meningkatkan kualitas pendidikan di Indonesia. Salah satu contoh yang dapat diterapkan pada pendidikan di Indonesia yaitu kerangka strategi menginovasi pendidikan di Malta (salah satu kota di Eropa). Malta membuat rancangan strategi pendidikan dengan kisaran target waktu 2014-2024. Adapun kisaran selama sepuluh tahun ke depan di Malta dalam merencanakan strategi pendidikannnya memiliki tujuan memiliki empat tujuan, yaitu: Pertama, mengurangi kesenjangan dalam hasil pendidikan antara laki-laki, perempuan dan antara siswa yang menghadiri sekolah yang berbeda, menurunkan jumlah berprestasi rendah dan meningkatkan berhitung, dan ilmu pengetahuan dan teknologi kompetensi, dan meningkatkan prestasi siswa. Kedua, dukungan prestasi pendidikan anak pada resiko kemiskinan dan dari status sosial-ekonomi rendah, dan mengurangi kejadian yang relatif tinggi awal sekolah-lulusan. Ketiga, meningkatkan partisipasi dalam seumur hidup belajar dan pembelajaran orang dewasa. Keempat, meningkatkan tingkat dari retainment siswa dan pencapaian lebih jauh, kejuruan, dan pendidikan tinggi dan pelatihan (Framework For The Education Strategy For Malta 2014-2024: 3).

\section{Metode}

Penelitian ini dilakukan melalui studi pustaka. Pengumpulan data dengan mengidentifikasi wacana dari buku-buku, makalah atau artikel, jurnal, koran, internet (web), dan informasi lainnya yang berhubungan dengan inovasi pendidikan. Analisis data menggunakan analisis deskripstif, analisis isi, dan analisis kritis. Analisis deskriptif yaitu mengumpulkan dan menyusun data kemudian data tersebut dianalisis. Analisis isi yaitu memanfaatkan seperangkat prosedur untuk menarik kesimpulan dari sebuah dokumen yang telah diperoleh. Sementara itu, analisis kritis yaitu penafsiran pada teks dan menyikapi makna dibalik peristiwa secara ilmiah.

\section{Hasil dan Pembahasan}

Adanya strategi yang matang dalam pendidikan maka akan mewujudkan hasil pendidikan yang maksimal pula. Salah satu perencanaan matang dalam strategi pendidikan adalah melalui inovasi di dalam dunia pendidikan. Inovasi sebagai rancangan awal yang diharapkan mampu mengakhiri 
hasil ketercapaian yang optimal dalam dunia pendidikan. Dengan demikian, adanya goals pendidikan yang direncanakan akan terwujud sebagaimana yang dirumuskan sebelumnya.

Pandangan Malta dalam “Framework For The Education Strategy 2014-2024" (2014: 529) mengemukakan bahwa terwujudnya pendidikan yang maju dan dinamis di Sekolah Dasar Pantai Quin, Australia Barat melalui rancangan 24 strategi melakukan inovasi dalam dunia pendidikan. Kedua puluh empat strategi ini meliputi komponen pedagogi, organisasi, dan nonakademik. Komponen pedagogi mengacu pada setiap strategi yang membutuhkan guru untuk mengadopsi metode pengajaran atau praktek untuk diterapkan. Komponen organisasi mengacu pada kebutuhan dan dukungan dari administrasi sekolah, lembaga pendidikan atau kelompok pemerintah untuk menerapkan strategi. Komponen non-akademik mengacu pada setiap strategi yang memiliki manfaat non-akademik. Adapun kedua puluh empat strategi pendidikan di Sekolah Dasar Pantai Quinn, Australia Barat adalah sebagai berikut;

Pertama, Personalisasi adalah sekolah yang memperhatikan pembelajaran pribadi akan melakukan segala upaya untuk memberikan pendidikan menggunakan berbagai cara dan metode untuk melibatkan semua siswa. Berikut lima kecerdasan manusia memiliki: (a) Kognitif/Analitik, (b) Tubuh/Kinestetik, (c) Tata Ruang, (d) Musik, (e) "pintar" atau memiliki IQ tinggi. Kelima aspek tersebut memang merupakan jenis kecerdasan kognitif yang tidak menjamin siswa untuk siap menghadapi tantangan hidup. Maka, lingkungan belajar yang dipersonalisasi tidak hanya mengembangkan keterampilan kognitif dan analitis, tetapi bagaimana pemerintah mewujudkan perkembangan kecerdasan anak untuk menjadi warga negara yang bertanggung jawab.

Kedua, Kelas Multi Usia. Pengelompokan multi usia (di dalam dan luar "ruang kelas") dirasa lebih cocok untuk mengatur populasi siswa. Di Sekolah Dasar Pantai Quinn di Australia Barat, multi-usia ruang kelas dengan tujuan siswa menjadi mandiri, pembelajaran tidak hanya berpusat pada guru tradisional, tapi siswa menjadi lebih interpersonal, intrapersonal, naturalis, dan eksistensial dalam mengeskpresikan bakat, minat, dan kemampuannya di kelas.

Ketiga, Belajar Masyarakat Kecil. Ada istilah "Ketika datang ke sekolah, ada bukti bahwa lebih kecil, lebih baik". Artinya yaitu setiap siswa merasa bahwa dia adalah bagian dari masyarakat di kelas atau sekolahan. Sehingga dengan harapan bahwa sekolah menjadi rumah kedua setelah di rumah.

Keempat, Belajar Kelompok Sebaya. Siswa dapat mengembangkan jangka panjang positif yaitu hubungan dengan teman sebaya dan teman yang peduli. Hal ini bertujuan agar mereka 
untuk bekerja dengan baik untuk saling membantu teman yang masih mengalami kesulitan belajar.

Kelima, Komunitas Belajar Kelompok Kecil dengan kelompok lain. Salah satu organisasi seperti struktur berfungsi seperti sebagai seorang penasehat. Sementara komunitas belajar kecil menghapus individualis dalam kelompoknya yang merasa bahwa hanya kelompoknya paling baik sendiri atau paling unggul. Maka dari itu, menunut mereka antar kelompok untuk saling bekerjasama. Masing-masing tidak merasa unggul dengan kelompoknya, jadi saling memberikan mentor (tutorial teman kelompok sebaya). Siswa dengan demikian dapat mengembangkan potensi belajar kelompok dalam jangka panjang secara positif dengan teman kelompok sebaya lainnya.

Keenam, Multidisiplin Kurikulum dengan Blok Penjadwalan. Penjadwalan blok alternatif cara untuk memecah hari sekolah menjadi segmen waktu yang lebih besar yang memungkinkan siswa untuk menikmati belajar yang lebih kaya pengalaman. Kata "multidisiplin" adalah cara mewah untuk mengatakan "nyata".

Ketujuh, Pembelajaran Kooperatif. Pembelajaran kooperatif adalah sistem agar siswa menjadi baik, termotivasi dan bahkan bisa menjadi seorang motivator. Hal ini memberikan pergeseran tanggung jawab belajar dari guru kepada siswa. Selain itu, pembelajaran kooperatif menghapus istilah "Kita Versus Mereka". Dengan demikian mentalitas organisasi sekolah mendorong dan menciptakan serta menempatkan dinamis pada siswa untuk diberdayakan dan bersemangat.

Kedelapan, Belajar Berbasis Proyek. Siswa tidak hanya memperoleh teori dalam pembelajaran, akan tetapi melakukan praktik dan mengaplikasikan teori tersebut sesuai fenomena yang terjadi saat ini. Keuntungan yang diperoleh dari adanya belajar berbasis proyek adalah mengembangkan keterampilan kolaborasi antara teori dan fenomena empiris.

Kesembilan, Rekan Instruksi. Teknik ini melibatkan guru memberikan pertanyaan ke seluruh kelas. Setiap siswa diberikan waktu untuk berpikir tentang pertanyaan dan merumuskan jawabannya sendiri. Kemudian, guru meminta siswa untuk mendiskusikan jawaban mereka dengan siapa pun yang duduk di samping mereka, setelah itu, setiap siswa diminta untuk memberikan jawaban ke pertanyaannya sekali lagi. Manfaat dari instruksi rekan mempertajam pengetahuan dan pemahaman siswa terhadap mata pelajaran melalui diskusi dengan rekanrekan siswa. 
Kesepuluh, Tim Pengajaran. Team teaching bermanfaat karena membuat mengajar profesi secara bersama untuk menyatukan persepsi pembelajaran yang inovatif. Mengajar tim juga memfasilitasi penggunaan penjadwalan blok yang dibahas pada point ke-6. Secara filosofis, hadirnya team teaching dapat menumbuhkan mentalitas siswa yang tidak hanya terfokus pada guru pokok.

Kesebelas, Community Service Learning. Community Service Learning diistilahkan sebagai Kelompok Kerja Nyata (KKN). Artinya, bahwa siswa memperoleh pelajaran penting dan lebih siap untuk menghadapi tantangan perguruan tinggi, mempertajam dan memperkuat sosial serta mengasah keterampilan teknis mereka dengan harapan dapat bermanfaat bagi dunia nyata setelah kuliah.

Kedua belas, Looping Kemitraan. Stategi pendidikan yang bekerjasama dengan perusahaan atau lembaga kerja tertentu unutk memaksimalkan belajar siswa. Tindakan tersebut biasa disebut dengan proses magang siswa di suatu lembaga kerja. Semacam koneksi nyata ke dunia kerja tersebut membuat belajar teori yang lebih bermakna bagi siswa.

Ketiga belas, Business untuk Penilaian, Sumber Daya dan Pendanaan. Dave, guru seni di California, membangun program animasi world renowned dalam bukunya Los Angeles sekolah tinggi oleh bermitra dengan studio utama Hollywood. Studio menyediakan peralatan khusus serta ahli bantuan kepada sekolah untuk mendukung siswa. Terkadang seluruh sekolah menciptakan dukungan bisnis. Misalnya, CART (Pusat Penelitian Lanjutan dan Teknologi di Clovis, CA) adalah sekolah tinggi publik yang sebagian besar disponsori oleh perusahaan terkemuka. Dengan demikian, sekolah memiliki kerjasamaa kemitraan guna menghasilkan produk langsung yang ter-cover dengan perusahaan tertentu untuk nilai tambahnya.

Keempat belas, Sambungan Global. Tidak semua sekolah dapat mengambil keuntungan dari kedekatan terkait industri seperti Dave, guru di Los Angeles. Dengan munculnya pembelajaran jarak jauh, memungkinkan bagi mereka untuk mencapai ahli mana pun. Sekolah yang semakin menggunakan jarak kapasitas belajar, mereka menginstal bagian dari teknologi infrastruktur untuk mencapai dimensi nasional dan internasional. Seperti jaringan global, baiknya bukan hanya karena membawa keahlian untuk sekolah mereka, tetapi juga karena untuk menempa hubungan antara siswa seluruh dunia berdasarkan tujuan bersama dan aspirasi.

Kelima belas, Laptop dan Teknologi Wireless untuk belajar dimanapun dan kapanpun. Dengan teknologi, belajar dengan cepat menjadi pengalaman multi-media yang tuntutannya tidak hanya mencakup teknologi know-how, tetapi juga keterampilan artistik. Terlepas dari 
subjek menjadi studi, tuntutan yang sekarang sedang ditempatkan pada semua siswa untuk mempresentasikan hasil kerja mereka secara profesional, kini membutuhkan kompetensi artistik. Dengan menggabungkan kemampuan artistik dan kompetensi teknologi, siswa dapat memperluas karier yang mereka pilih.

Keenam belas, Keterlibatan Orang tua. Orang tua cenderung menolak perubahan yang membawa mereka di luar zona nyaman. Ada sentimen umum bahwa ketika anak-anak kita mendatangi pendidikan, maka lebih baik hidup dengan sistem yang ada dengan segala permasalahannya daripada "percobaan" yang memberlakukan ide-ide baru. Satu-satunya cara untuk mengatasi rasa takut ini adalah dengan menjalin mitra dengan orang tua sehingga mereka mampu mengembangkan pemahaman yang konkrit guna menjadi mitra aktif dalam perubahan proses.

Ketujuh belas, Siswa menampilkan Pertunjukan. Bermain adalah bentuk sah dari pembelajaran dan satu-satunya hal yang menarik ketika siswa kecewa dengan proses pendidikan. Anak-anak adalah pemain alami, dan ini adalah salah satu cara untuk memperkenalkan bermain ke dalam persamaan belajar. Hal ini merupakan salah satu cara untuk melibatkan anak-anak untuk menjadi lebih aktif dan termotivasi di sekolah. Pertunjukan dapat berkisar dari sandiwara dadakan di kelas untuk menguraikan tahap kualitas profesional dan produksi seperti siswa menulis, memproduksi, dan bertindak seri drama komedi.

Kedelapan belas, Kurikulum Kecakapan Hidup (Non-Akademik). Kemampuan untuk menyelesaikan konflik secara damai adalah keterampilan yang sangat penting, sehingga diharapkan siswa dapat memberikan resolusi konflik dengan sendirinya, baik konflik dengan anggota keluarga, teman, dan rekan belajarnya. Hal tersebut tercermin dalam kurikulum seperti adanya pendidikan karakter. Pendidikan karakter sebagai kecakapan hidup siswa terwujud dalam sifat peduli, kebajikan sipil dan kewarganegaraan, kejujuran, keadilan, hormat, tanggung jawab, dan kepercayaan.

Kesembilan belas, Konseling Karier Bermakna. Sekolah diharapkan dapat membangun kekuatan siswa, kemampuan dan mendorong mereka untuk mengejar kepentingan karier yang mereka pilih. Konseling karier artinya bahwa sekolah dapat menjadi lembaga yang mampu memberikan advokasi terhadap karier yang dikehendaki oleh siswa. Sekolah dapat memberikan pengarahan terkait pentingnya meniti karier setelah sekolah guna menjamin keberlangsungan hidup dalam taraf ekonomi. 
Kedua puluh, Konseling Sosial/Emosional. Penelitian telah menunjukkan bahwa sosial dan keterampilan emosional adalah penentu keberhasilan hidup. Oleh karena itu, sekolah harus mampu mewujudkan pembelajaran yang berorientasi terhadap keterampilan sosialisasi siswa sejak dini.

Kedua puluh satu, Belajar terbuka. Tujuan nyata pembelajaran adalah yang tidak mengurangi harkat manusiawi. Artinya bahwa siswa dalam tahap usia anak-anak dan dewasa perlu untuk bergerak dan mencari pengalaman luar. Karena pada dasarnya tujuan belajar terbuka adalah agar siswa mampu belajar lebih otentik sekaligus meningkatkan dan mengembangkan potensi fisik, sosial, emosional, dan rohani.

Kedua puluh dua, Pendidikan untuk melayani Kebutuhan Siswa. Situasi bahwa sekolah/lembaga pendidikan dimaksudkan adalah untuk "melayani" populasi siswa. Lembaga harus mengembangkan otonomi siswa guna mempersiapkan siswa untuk memiliki totalitas tanggung jawab sebagai warga masyarakat.

Kedua puluh tiga, Penilaian Berbasis Portofolio. Tujuan utama dari portofolio adalah menyediakan siswa untuk memiliki pengalaman belajar yang dibuktikan dengan dokumen administrasi. Portofolio siswa di sekolah menjadi media yang berharga untuk membantu siswa masuk ke perguruan tinggi yang baik dan dunia kerja.

Keduapuluh empat, Paradigma Baru Bangunan Sekolah. Paradigma baru sekolah menantang keunggulan mengenai struktur bangunan seperti ketersedian sarana dan prasarana dalam menunjang pembelajaran di kelas. Sebagai contoh masing-masing jenjang kelas 1, 2, 3 dan seterusnya ada "blok bangunan" masing-masing. Selain itu adanya bunyi lonceng atau alarm/bel sebagai tanda waktu mulai dan berakhirnya pembelajaran. Di samping itu juga, ketika merancang sebuah sekolah, maka turut berkaitan dengan fasilitas ruang kelas (meja, kursi, papan tulis, dan sarana penunjang pembelajaran lainnya).

\section{Kesimpulan}

Usaha dalam menginovasi pendidikan harus diimbangi dengan adanya proses kebijakan pendidikan yang berkesinambungan dan saling mendukung satu sama lain. Proses kebijakan dapat digambarkan sebagai suatu sistem yang terdapat input, proses dan output. Input proses kebijakan adalah isu kebijakan atau agenda pemerintah, sedangkan proses kebijakan berupa perumusan formulasi kebijakan dan implementasi kebijakan. Isu dan formulasi kebijakan merupakan proses politik yang dilakukan elit politik dan kelompok-kelompok penekan. Jurus jitu 
menginovasi Pendidikan di Indonesia dapat diterapkan melalui 24 strategi seperti di Malta antara lain melalui Personalisasi, Kelas Multi Usia, Belajar Masyarakat Kecil, Belajar Kelompok Sebaya, Komunitas Belajar Kelompok Kecil dengan kelompok lain, Multidisiplin Kurikulum dengan Blok Penjadwalan, Pembelajaran Kooperatif, Belajar Berbasis Proyek, Rekan Instruksi, Tim Pengajaran, Community Service Learning, Looping Kemitraan, Business untuk Penilaian, Sumber Daya dan Pendanaan, Sambungan Global, Laptop dan Teknologi Wireless untuk Belajar Dimanapun dan Kapanpun, Keterlibatan Orang tua, Siswa menampilkan Pertunjukan, Kurikulum Kecakapan Hidup (Non-Akademik), Konseling Karir Bermakna, Konseling Sosial/Emosional, Belajar terbuka, Pendidikan untuk melayani Kebutuhan Siswa, Penilaian Berbasis Portofolio serta Paradigma Baru Bangunan Sekolah.

\section{Aknowledgment}

Pada kesempatan kali ini penulis mengucapkan terimakasih kepada pihak yang sudah membantu menyelesaikan penelitian ini dan laporan ini, Dr. (c) Septiana Agustin, Dr (c) Ryzal Perdana, Dr.(c) Jauhan Budiwan, dan juga kepada Dosen dan rekan prodi Pendidikan Guru Sekolah Dasar Universitas Veteran Sukoharjo Jawa Tengah yang sudah bersedia membantu kelancaran penelitian ini.

\section{Referensi}

Ace Suryadi dan H.A.R Tilaar. (1993). Analisis Kebijakan Pendidikan Suatu Pengantar. Bandung: Remaja Rosdakarya.

Direktorat Jendral Pendidikan Tinggi. 2012. Rencana Strategis (2010-2014). Jakarta: Dikti.

Depdikbud. (1990). Kamus Besar Bahasa Indonesia. Jakarta: Balai Pustaka.

Departemen Pendidikan Nasional. (2002). Pengembangan kurikulum berbasis kompetensi II. Jakarta: Balitbang Pusat Kurikulum.

Departemen Pendidikan Nasional. (2003). Pelayanan Profesional Kurikulum 2004 Kurikulum Berbasis Kompetensi. Jakarta: Balitbang Pusat Kurikulum.

Departemen Pendidikan Nasional. (2010) . Peraturan Menteri Pendidikan Dan Kebudayaan Republik Indonesia Tentang Pendidikan Menengah Universal.

Everett M, Rogers. 2003. Diffusion of Innovation 5th Edition. New York: Free Press.

Endang.W. (2008). Perilaku dan Manajemen Organisasi. Jurnal Ilmu Administrasi No. 1 Volume 1 2008.

Framework for the education strategy for malta (2014-2024): Sustaining foundations, creating alternatives, increasing employability.

Subandi. (2005). Sistem Ekonomi Indonesia. Bandung: Alfabeta. 